\title{
In Situ Synthesis of Structural Hierarchy Flowerlike Zeolite and Its Application for Fluoride Removal in Aqueous Solution
}

\author{
Zhihan Tian ${ }^{1}$ and Yiqun Gan ${ }^{1,2}$ \\ ${ }^{1}$ School of Environmental Studies, China University of Geosciences, Wuhan 430074, China \\ ${ }^{2}$ Key Laboratory of Biogeology and Environmental Geology, China University of Geosciences, Wuhan 430074, China \\ Correspondence should be addressed to Yiqun Gan; yiqungan@cug.edu.cn
}

Received 15 August 2019; Accepted 18 October 2019; Published 18 November 2019

Academic Editor: Yong Ding

Copyright ( 2019 Zhihan Tian and Yiqun Gan. This is an open access article distributed under the Creative Commons Attribution License, which permits unrestricted use, distribution, and reproduction in any medium, provided the original work is properly cited.

\begin{abstract}
A three-dimensional hierarchically structured flowerlike zeolite was synthesized using naturally occurring nanohalloysite (HNT) by hydrothermal methods. Halloysite a hydrated aluminum silicate with nanohollow morphology, microporosity, and environmentally friendly properties was chosen to be the sole precursor. The morphology and structure of the composite that was prepared was characterized using XRD, FT-IR, BET, TG, SEM, HRTEM, and NMR. SEM and HRTEM images indicated that the synthesized zeolite has a flowerlike hierarchical structure, with well-defined edges and uniform pore channels. FT-IR and NMR spectra indicated that different species of silicon and aluminum were present in the synthesized zeolite. The zeolite was applied in fluoride $\left(\mathrm{F}^{-}\right)$removal from aqueous solutions. Single-factor studies, including the initial concentration of $\mathrm{F}^{-}$, initial adsorbent concentration, and the effect of $\mathrm{pH}$ value on the adsorption properties, were investigated to evaluate the removal behavior of $\mathrm{F}^{-}$by the zeolite. The zeolite exhibited strong adsorption properties for fluoride ions $\left(\mathrm{F}^{-}\right)$, with an adsorption capacity up to $161 \mathrm{mg} \mathrm{g}^{-1}$. The pseudo-second-order kinetics and Freundlich models were the best fit to the kinetics and isotherm experimental data, respectively.
\end{abstract}

\section{Introduction}

Zeolites are aluminum silicate crystals with a framework structure of three-dimensional tetrahedral units that have abundant micropores with molecular dimensions. Furthermore, this porous crystalline solid has high surface area for unique reactions and adsorption [1]. This combination of properties makes zeolites suitable as adsorbents for a large variety of pollutants. Various preparation methods have been studied. Usually, zeolites are prepared with various silica and alumina sources as a precursor gel under conditions of high pressure and high temperature. Then, various surfactants were added to obtain uniform porous structure, including cationic surfactant cetyltrimethylammonium bromide (CTAB) and hexadecyldimethylammonium chloride (TPHAC) [2-4]. Regardless, the organic/inorganic agents that are typically used are expensive. Therefore, an easy and dependable method is ideally required for in situ synthesis of hierarchical structural adsorbents.
Various morphologies of the nanomaterials [5-8] have been synthesized, and their associated defect properties have been investigated. However, three-dimensional (3D) flowerlike structures composed of hierarchically assembled nanosized building blocks, where the total size of the nanostructures is in the micrometer scale, have several remarkable advantages for adsorption compared with adsorbents with other morphologies, including high surface area, easy mass transformation, and easy separation. A method with lower cost $[9,10]$, fewer organic/inorganic agents, and easier reaction conditions is required, and the new obtained zeolite must have a hierarchical morphology.

Halloysite, a multiple-layered aluminosilicate clay with a natural nanohollow shape, consists of one alumina octahedron sheet and one silica tetrahedron sheet alternating in a $1: 1$ stoichiometric ratio. The structure and composition of halloysite are similar to kaolinite, except that the unit layers of halloysite are separated by a monolayer of water molecules $[6,11]$. Due to its high specific surface area, nanohollow 
morphology, uniform micropore structure, and natural resources of silicon and aluminum, halloysite could be a promising candidate for the preparation of highly pure zeolite.

Groundwater is an essential resource for ecosystems and human beings. However, some anions in the groundwater are undesirable and often responsible for serious environmental and health problems [12]. Fluoride $\left(\mathrm{F}^{-}\right)$from natural sources and from anthropogenic activities such as industry and agriculture is one such problematic anion [13-15]. Skeletal fluorosis (including bone deformities), dental fluorosis, and kidney and liver malfunction are some of the consequences of exposure to drinking water high in $\mathrm{F}^{-}$[16-19]. High $\mathrm{F}^{-}$ concentrations $(>1.5 \mathrm{mg} / \mathrm{L}$, the WHO prescribed limit for drinking water) in groundwater that is used for drinking can adversely impact the health of people, which has been occurring in China [20-25].

Industrial and domestic wastewater treatment systems usually employ biological (activated sludges), physical (adsorption, filtration, flocculation, etc.), and chemical (coagulation and electrolysis) processes, which are inefficient in terms of fluoride removal $[25,26]$. For fluoride removal, previous studies present various remediation options, including precipitation-coagulation $[27,28]$, membrane-based processes [29, 30], ion exchange [31, 32], and adsorption [33]. However, most of these adsorbents involve complicated synthesis processes or are not suitable for large-scale application due to their cost. The exception is zeolite, which is a low-cost material and has been widely used [34].

The goals of this work are (i) to find an optimum method for the synthesis of hierarchical flowerlike zeolite using halloysite and (ii) to investigate its adsorption potential for $\mathrm{F}^{-}$. The prepared zeolite was characterized using various methods, including XRD, FT-IR, and NMR. And the prepared zeolite was used as an adsorbent for fluoride removal from aqueous solution. The factors impacting removal efficiency, including $\mathrm{pH}$, initial $\mathrm{F}^{-}$concentration, equilibrium time, and mass of adsorbent, were evaluated. Kinetics and isotherm experiments were conducted.

\section{Materials and Methods}

2.1. Raw Material and Chemicals. Natural halloysite, used as silicon and aluminum sources in this work, was purchased from Clay Mineral in Jiangsu Province, China. All other chemicals were of analytical grade and purchased from Sinopharm Chemical Reagent Co., Ltd.

2.2. Preparation of Zeolite. The halloysite was dispersed with $0.2 \mathrm{wt} \%$ sodium hexametaphosphate (used as a dispersant) and stirred at $60^{\circ} \mathrm{C}$ for $12 \mathrm{~h}$. After resting for $24 \mathrm{~h}$ at room temperature, the impurities (gibbsite, quartz, and feldspar) were removed and the remainder was dried. A certain amount of pure halloysite was added into $2 \mathrm{wt} \% \mathrm{NaOH}$ solution $(60 \mathrm{~mL})$. The mixed solution was magnetically stirred for $10 \mathrm{~min}$ until the reaction gel was homogenous. Then, the mixture was placed into a Teflon reactor $(80 \mathrm{~mL})$ and crystallized at $120^{\circ} \mathrm{C}$ for $24 \mathrm{~h}$. The solid powder was filtered and washed with distilled water and then dried in a temperature-controlled oven at $70^{\circ} \mathrm{C}$ for $12 \mathrm{~h}$. Then, the products were obtained and labeled as zeolite $\mathrm{NaA}$.

2.3. Characterization. The crystalline characteristics of the samples were investigated using wide-angle X-ray diffraction (XRD). The diffraction patterns were obtained using a $\mathrm{D} / \mathrm{max} 2550 \mathrm{X}$-ray diffractometer (Rigaku, Japan) with $\mathrm{Cu}$ $\mathrm{K} \alpha$ radiation $(\lambda=0.15406 \mathrm{~nm})$ monitoring from $10^{\circ}$ to $70^{\circ}$. The operation voltage and current were maintained at $40 \mathrm{kV}$ and $34 \mathrm{~mA}$, respectively. The morphology of the zeolite $\mathrm{NaA}$ was characterized using Transmission Electron Microscopy (TEM) and Scanning Electron Microscopy (FE-SEM). FE-SEM was performed using a Hitachi S-4800 SEM (Hitachi), operating in backscatter mode at $20 \mathrm{kV}$ acceleration voltage. The TEM analysis utilized a Tecnai G220 electron microscope (FEI, Czech Republic) operating at an acceleration voltage of $120 \mathrm{kV}$. High-resolution TEM (HRTEM) was performed using a JEM-2010 (HR) (JEOL, Japan) at an acceleration voltage of $200 \mathrm{kV}$.

Fourier Transformed Infrared Spectroscopy (FT-IR) was recorded on an Equinox 55 spectrometer in the range 400 $-4000 \mathrm{~cm}^{-1}$. Nuclear magnetic resonance (NMR) was performed using a Bruker Avance III at the National Center for Magnetic Resonance in Wuhan. Surface areas and pore distributions were measured by nitrogen adsorption and desorption at $473 \mathrm{~K}$ using an ASAP 2020 surface area and pore analyzer (Micromeritics, USA). Thermal gravimetric (TG) data were measured using a STA 449 F3 Jupiter (NETZSCH, Germany) by heating a certain weight of sample in a silica crucible from room temperature to $800^{\circ} \mathrm{C}$ at a heating rate of $10^{\circ} \mathrm{C} \mathrm{min}^{-1}$.

2.4. Adsorption Experiments. The prepared zeolite NaA was used as adsorbent for fluoride removal. A certain amount of adsorbent was added into a fluoride solution, which was placed into an Erlenmeyer flask and shaken in a thermo shaker incubator. The initial and remaining fluoride ion concentrations were determined by an ion meter (PXSJ-226, INESA Scientific Instrument Co., Ltd).

A series of single-factor studies were performed by maintaining the volume of the solution at $50 \mathrm{~mL}$, the temperature at $35^{\circ} \mathrm{C}$, and the reaction time at $24 \mathrm{~h}$. The influence of $\mathrm{pH}$ on the $\mathrm{F}^{-}$adsorption was investigated by varying the $\mathrm{pH}$ from 2.0 to 9.0 using $10 \mathrm{mg}$ of adsorbent and a $20 \mathrm{mg} \mathrm{L}^{-1} \mathrm{~F}^{-}$solution. The $\mathrm{pH}$ values were adjusted using $0.1 \mathrm{M} \mathrm{HCl}$ or $0.1 \mathrm{M} \mathrm{NaOH}$ solutions. The effect of adsorbent mass was studied by varying the concentrations of prepared zeolite $\mathrm{NaA}$ from 0.1 to $0.5 \mathrm{~g} \mathrm{~L}^{-1}$. The influence of the initial fluoride concentration on $\mathrm{F}^{-}$removal was studied by varying the initial concentrations from 1.05 to $51.7 \mathrm{mg} \mathrm{L}^{-1}$. The adsorption kinetics experiment was carried out using initial $\mathrm{F}^{-}$concentrations of $20 \mathrm{mg} \mathrm{L}^{-1}(\mathrm{pH} 2.0)$ and by shaking for durations ranging from 5 to $180 \mathrm{~min}$.

The amount of adsorption $q_{\mathrm{e}}\left(\mathrm{mgg}^{-1}\right)$ was calculated by the following equation:

$$
q_{\mathrm{e}}=\frac{\left(C_{\mathrm{o}}-C_{\mathrm{e}}\right) \times V}{m}
$$


where $C_{\mathrm{o}}$ and $C_{\mathrm{e}}(\mathrm{mg} / \mathrm{L})$ are the initial and equilibrium concentrations of $\mathrm{F}^{-}$in solution, respectively, $V(\mathrm{~L})$ is the volume of the solution, and $m(\mathrm{~g})$ is the dosage of adsorbents.

2.5. Regeneration of Zeolite NaA. $1 \mathrm{~g}$ of zeolite NaA loaded with fluoride was shaken with $0.5 \mathrm{~mol} \mathrm{~L}^{-1} \mathrm{NaOH}$ solution for $2 \mathrm{~h}$. The adsorbent was separated by filtration, and the residue on filter paper was washed with deionized water and dried at $70^{\circ} \mathrm{C}$ for $10 \mathrm{~h}$.

\section{Results}

3.1. Characterization. The X-ray diffraction patterns of unreacted halloysite powders indicate a d001 peak at $12.1^{\circ} 2$ $\theta$, which corresponds to a basal spacing of $7.3 \AA$ (Figure 1(a), B). The pattern is in good agreement with JCPDS data of card No. 29-1487. However, the X-ray diffraction pattern of the halloysite sample shows the occurrence of minor impurities, including characteristic peaks of quartz, gibbsite, and feldspar. After purification (Figure 1(a), A), compared with the X-ray pattern of raw material, no additional peaks were observed, indicating that impurities were removed and the crystallization of halloysite was pure.

The XRD patterns of the products obtained from hydrothermal reaction are shown in Figure 2. When treated with $2 \mathrm{wt} \% \mathrm{NaOH}$ solution by the hydrothermal method at $120^{\circ} \mathrm{C}$, the characteristic peaks of halloysite disappeared. All $\mathrm{XRD}$ peaks agree well with the characteristic peaks of zeolite $\mathrm{NaA}$ ( $\mathrm{Na}$ type, hydrated) by comparing the $d$-values of the products obtained with JCPDS data of card No. 39-0222. Zeolite $\mathrm{NaA}$ has several common peaks located at $7.14^{\circ}$, $10.10^{\circ}, 12.38^{\circ}, 16.20^{\circ}, 21.58^{\circ}, 23.92^{\circ}, 27.00^{\circ}, 29.82^{\circ}$, and $34.08^{\circ} 2 \theta$ in its XRD patterns. No additional peaks were observed, indicating the crystallization of pure-form zeolite $\mathrm{NaA}$. The XRD pattern of the crystals has a low background, strong intensities, and sharp peaks, indicating that the assynthesized zeolite $\mathrm{NaA}$ crystals are pure [6].

Halloysite crystals are hollow and open-ended nanotubes. The morphological parameters of the halloysite sample, measured from the TEM image (Figure 1(b)), are an average length of $0.5-3 \mu \mathrm{m}$, an inner diameter in the range of $20-50 \mathrm{~nm}$, and an average pore diameter of $10-55 \mathrm{~nm}$. The low-magnification SEM image (Figure 3(c)) indicates that the product consists of a large quantity of uniform nanostructures with diameters of $\sim 1 \mu \mathrm{m}$. No other morphologies can be observed, implying that a high yield can be achieved using the reaction conditions adopted by this method. Higher magnification SEM images (Figure 3(a)) provide more detailed exterior structural information of the zeolite $\mathrm{NaA}$, which is constructed of numerous interlaced nanosheets and forms a porous surface with an open hierarchical structure. The TEM image given in Figure 3(b) also shows that the flowerlike hierarchical structure of zeolite $\mathrm{NaA}$ is assembled from nanosheets, with the interstitial space of which forming mesopores and the edge morphology of the particle clearly revealing that each particle is composed of many densely packed nanocrystals oriented in the same direction. Moreover, in the growing process from Fig. S1, the morphology changes from hollow rods to sheets and finally to a hierarchical flowerlike morphology. In the highresolution TEM (HRTEM) image of the zeolite $\mathrm{NaA}$ (Figure 3(d)), the 2D lattice fringes can be clearly observed, which confirms the high crystallinity of the sample. The lattice fringe ( $d$-spacing is $\sim 7.1 \AA$, which is corresponding to plane222) fits the sample, implying good crystallization of the zeolite $\mathrm{NaA}$. Figure 3(e) indicates the main component elements ( $\mathrm{Al}, \mathrm{Si}, \mathrm{Na}, \mathrm{O})$. The hierarchical morphology contains uniform pore channels, which provide a greater surface area with active sites than halloysite and provide zeolite $\mathrm{NaA}$ with a greater potential for the adsorption of harmful ions.

Figure $4 \mathrm{a}$ is the FT-IR spectra of pure HNTs. The peaks at $3698 \mathrm{~cm}^{-1}$ and $3627 \mathrm{~cm}^{-1}$ are the stretching vibration absorption peaks of external hydroxyl ions on the $\left[\mathrm{SiO}_{4}\right]$ tetrahedral and $\left[\mathrm{AlO}_{6}\right]$ octahedral layers in halloysite [35-37]. The peaks at $1037 \mathrm{~cm}^{-1}, 754 \mathrm{~cm}^{-1}, 688 \mathrm{~cm}^{-1}$, and $468 \mathrm{~cm}^{-1}$ are stretching vibration and deformation vibration absorption peaks of the Si-O band. The $912 \mathrm{~cm}^{-1}$ peak is an Al$\mathrm{OH}$ band deformation vibration absorption peak. According to the FT-IR spectrum in Figure $4 \mathrm{~b}$, the characteristic zeolite bands appeared coincidentally with the disappearance of halloysite, including the asymmetric and symmetric T-O ( $T$ $=\mathrm{Si} / \mathrm{Al})$ stretch [38-40]. The bands in the region of 500$650 \mathrm{~cm}^{-1}$ are related to the presence of the double rings (D4R and D6R) in the framework structure [41]. The bands at 464 and 663 are assigned to the internal linkage vibrations of the $\mathrm{TO}_{4}(\mathrm{~T}=\mathrm{Si}$ or $\mathrm{Al})$ tetrahedron and to the asymmetric stretching, respectively, of zeolite $\mathrm{NaA}$ [42]. The typical bands of zeolite $\mathrm{NaA}$ are observed, representing the asymmetric and symmetric stretch (1444 and $\left.1005 \mathrm{~cm}^{-1}\right)$ and double rings $\left(565 \mathrm{~cm}^{-1}\right)$. The band at approximately $1647 \mathrm{~cm}^{-1}$ is attributed to the presence of the $\mathrm{H}_{2} \mathrm{O}$ mode and incomplete dehydration of the zeolite $\mathrm{NaA}$ samples [43]. Moreover, a broad peak at the $3000-3750 \mathrm{~cm}^{-1}$ range with a maximum at $3455 \mathrm{~cm}^{-1}$ appears in the FT-IR spectra that correspond to $\mathrm{Si}-\mathrm{OH}$ vibrations. All of the characteristic IR bands of the NaA zeolite are similar to the zeolite LTA studied by Zhao et al. $[6,44]$ and are in agreement with NMR data.

The ${ }^{29} \mathrm{Si}$ solid-state MAS NMR spectra of the halloysite (Figure 5(a)) reveal the type of silicon atoms in halloysite and zeolite $\mathrm{NaA}$. The sharp $-92.3 \mathrm{ppm}$ signal is assigned to Q3-type $\mathrm{Si}(\mathrm{OSi})_{3}\left(\mathrm{OAl}_{2}\right)$ sites, where each silicon has twosecond nearest octahedral aluminum from the nearby aluminum hydroxide layer of pure halloysite. We can see the same signals at zeolite $\mathrm{NaA}$ (-88.9 ppm, Figure 5(a), B). This demonstrates that alkali treatment does not change the $\mathrm{Si}$ atom structure. The ${ }^{27} \mathrm{Al}$ solid-state magic-angle spinning (MAS) nuclear magnetic resonance $\left({ }^{27} \mathrm{Al}\right.$ MAS NMR) spectra of the halloysite and hierarchical structure zeolite $\mathrm{NaA}$ samples are shown in Figure 5(b). The spectrum of the halloysite (Figure 5(b), A) exhibits a typical resonance peak at $4.1 \mathrm{ppm}$ with respect to $\mathrm{Al}\left(\mathrm{H}_{2} \mathrm{O}\right)_{6}{ }^{3+}$, which is assigned to octahedral Al. For the zeolite NaA (Figure 5(b), B), the spectrum shows two peaks at $4.0 \mathrm{ppm}$ and $59.0 \mathrm{ppm}$, which are assigned to octahedral $\mathrm{Al}$ and tetrahedral $\mathrm{Al}$ coordinated to oxygen. The transformation suggests that the $\mathrm{Al}$ atom structure changes from octahedral Al to tetrahedral Al. It is suggested that alkali will dissolve $\left[\mathrm{SiO}_{4}\right]$ octahedral layers and thus cause the rupture and collapse of $\left[\mathrm{AlO}_{6}\right]$ tetrahedron 


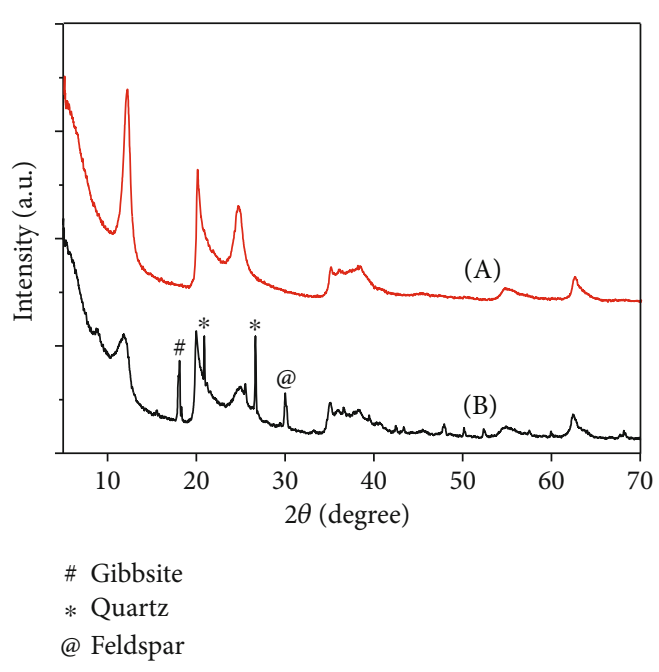

(a)

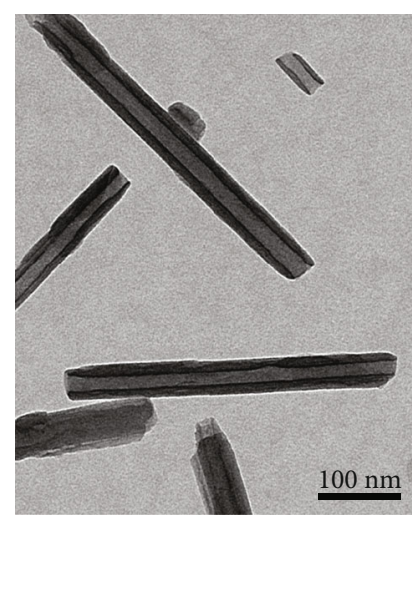

(b)

Figure 1: X-ray diffraction pattern and TEM image of raw B and pure A halloysite.

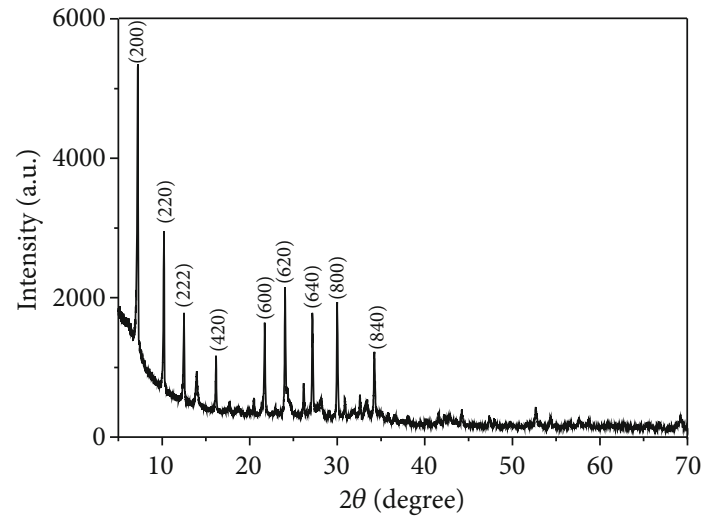

FIGURE 2: XRD pattern of prepared zeolite NaA.

layers. Moreover, the spectrum does agree with the zeolite NaA structure very well.

Nitrogen adsorption and desorption analyses were conducted to investigate the surface area and pore volume of natural and alkali-treated halloysite. According to IUPAC [45], both isotherms can be classified as being of type IV, which are characteristic of materials with well-developed mesoporous structures. The small crystallite size and hollow structure give halloysite a specific surface area of approximately $32.7 \mathrm{~m}^{2} \mathrm{~g}^{-1}$. Due to the dissolution of $\left[\mathrm{SiO}_{4}\right]$ tetrahedral layers [46], the alkali treatment increases the BET surface area from $32.7 \mathrm{~m}^{2} \mathrm{~g}^{-1}$ of pure halloysite to $61.8 \mathrm{~m}^{2} \mathrm{~g}^{-1}$ of zeolite $\mathrm{NaA}$. The isotherm of zeolite $\mathrm{NaA}$ has a more obvious hysteresis loop than that of pure halloysite, which is due to the capillary condensation of $\mathrm{N}_{2}$ at a relative pressure $P / P_{0}$ of $0.5-1.0$ and confirms the coexistence of mesopores in the sample. The pore size distribution of zeolite NaA shown in Figure 6(b) (inset) indicates that most pores are distributed in the size range of $2-50 \mathrm{~nm}$, confirming the mesoporosity features of the material. The size of the mesopores in the flowerlike hierarchical structure zeolite $\mathrm{NaA}$ is estimated to be $16.4 \mathrm{~nm}$ by using the Barrett-Joyner-Halenda (BJH) method.

Thermal gravimetry (TG) curves of pure halloysite and alkali-treated products are shown in Figure 7. Because of the suspension effect of the samples, there are raised parts at the beginning of the curves, but they do not impact the analysis. The TG curve of pure halloysite (Figure 7 a) exhibits two main weight loss stages. The first stage in the TG curve starts at approximately $50^{\circ} \mathrm{C}$ and ends at about $150^{\circ} \mathrm{C}$, which can be attributed to the dehydration of physisorbed water and interlayer water. The second stage of the TG curve corresponds to the dehydroxylation of structurally incorporated water and starts at $400^{\circ} \mathrm{C}$ and ends at approximately $500^{\circ} \mathrm{C}$. The TG curves of the flowerlike hierarchical structure zeolite $\mathrm{NaA}$ (Figure $7 \mathrm{~b}$ ) exhibit only one main weight loss stage, starting at approximately $100^{\circ} \mathrm{C}$ and ending at about $250^{\circ} \mathrm{C}$, which may be attributed to the dehydration and destruction of halloysite during the alkali treatment. It is suggested that the structural hydroxyl groups in the $\left[\mathrm{SiO}_{4}\right]$ tetrahedral layer are removed along with the dissolution of $\mathrm{Si}^{4+}$.

\subsection{Batch Adsorption Studies}

3.2.1. Effect of $p H$, Initial F Concentration, Adsorbent Mass, and Adsorption Time. The impact of solution $\mathrm{pH}$ is an important parameter for understanding the interaction between target molecules and adsorbents. The $\mathrm{pH}$ variation can promote changes in the surface charges of adsorbents and influence the protonation of functional groups present on the surfaces of materials. The experimental result in Figure 8(a) indicates that the adsorbent exhibited better performance in the strong acidic medium ( $\mathrm{pH}$ of approximately 2 ). It can be seen that the adsorption capacity of fluoride decreased with $\mathrm{pH}$ values increasing from 2 to 9 , which may be attributed to that the hydroxyl ions and fluoride 

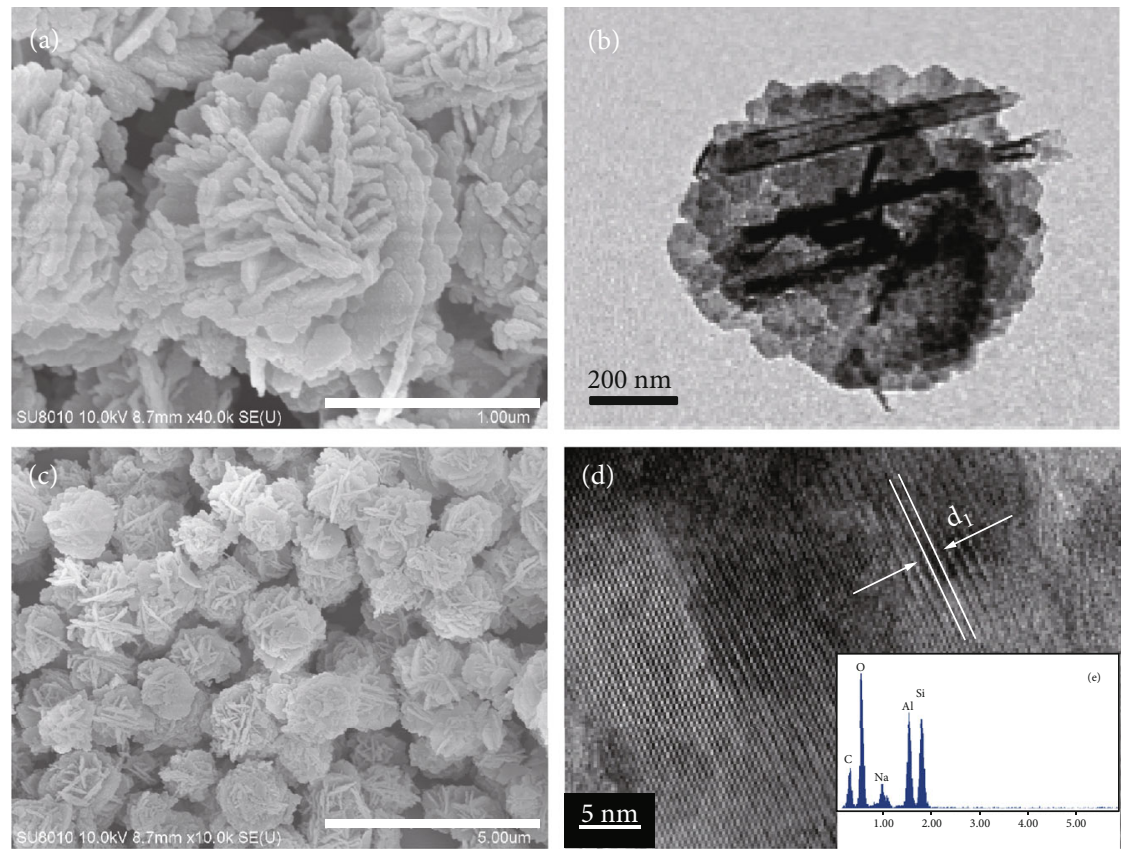

Figure 3: The SEM images of zeolite $\mathrm{NaA}(\mathrm{a}, \mathrm{c})$, TEM image and lattice fringes (b, d), and the elemental composition (e).

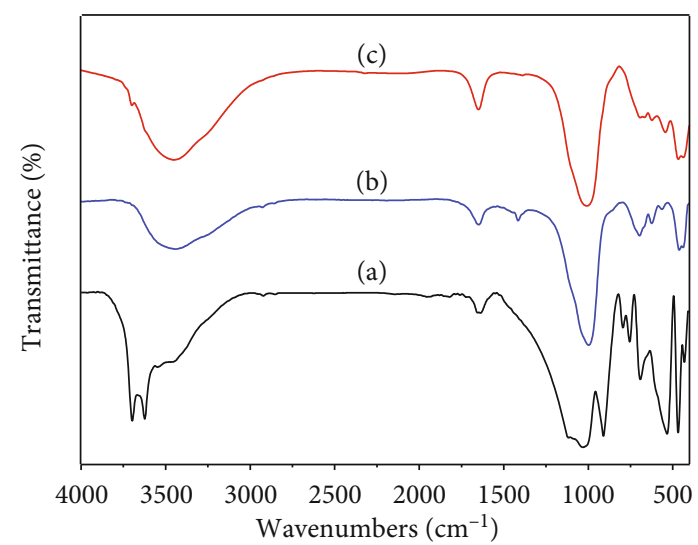

Figure 4: FT-IR spectra of pure HNTs (a), zeolite NaA (b), and zeolite $\mathrm{NaA}$ after reaction (c).

would compete on the active adsorption sites. The zeta potential is positive in the $\mathrm{pH}$ range of 2-3.7, which indicates that it is beneficial for fluoride removal at lower $\mathrm{pH}$ due to the electrostatic attraction between fluoride and adsorbent. When $\mathrm{pH}$ is over 3.7, the zeta potential is negative. The fluoride adsorption capacity also decreased due to the electrostatic repulsion that exists between the fluoride and the surface of adsorbent (Figure 9). Initial concentrations of $1.05-51.7 \mathrm{mg} \mathrm{L}^{-1}$ were selected, which are higher than normally found in groundwater. Figure $8(\mathrm{~b})$ shows that the adsorption capacity increases with increasing concentration and the maximum adsorption capacity can reach up to $144 \mathrm{mg} \mathrm{g}^{-1}$. Figure 8(c) shows that under the same initial concentration, adsorption efficiency increases slowly from 52.5\% to $68.8 \%$, but the adsorption capacity defined as the amount adsorbed per unit mass decreases. It is readily understood that the number of available adsorption sites increases by increasing the adsorption dose and thus results in an increased removal efficiency. The decrease in adsorption density with increasing adsorbent dose is mainly due to unsaturation of adsorption sites through the adsorption reaction [47]. According to this study, the most suitable adsorbent concentration is approximately $10 \mathrm{mg}$ per $50 \mathrm{~mL}$. Figure 8(d) shows that the adsorption reaches equilibrium in $30 \mathrm{~min}$. Compared to most of previous studies about fluoride adsorbents (Table 1), the absorption property (adsorption capacity and equilibrium time) of zeolite $\mathrm{NaA}$ is much better.

3.2.2. Adsorption Kinetics. Kinetics studies can provide useful information regarding the speed and mechanism of an adsorption process. The experimental kinetics data were fitted with nonlinear forms of pseudo-first-order and pseudo-second-order models as described by Equation (2) and Equation (3), respectively.

$$
\begin{gathered}
\ln \left(q_{\mathrm{e}}-q_{t}\right)=\ln q_{\mathrm{e}}-k_{1} t, \\
\frac{t}{q_{t}}=\frac{1}{k_{2} q_{\mathrm{e}}{ }^{2}}+\frac{t}{q_{\mathrm{e}}},
\end{gathered}
$$

where $q_{t}$ is the amount of adsorbed fluoride (mg) per unit mass of adsorbent $(\mathrm{g})$ at time $t(\mathrm{~min}), q_{\mathrm{e}}$ is the adsorption capacity of the adsorbent (at equilibrium), and $k_{1}$ and $k_{2}$ are the rate constants for the pseudo-first-order and pseudo-second-order models, respectively.

Table 2 presents kinetics parameters for both models and shows that the pseudo-second-order model fits well with experimental data and the plots are shown in Fig. S2a, b. The adsorption capacity calculated $\left(q_{\mathrm{e}}\right.$, cal $)$ by the pseudo- 


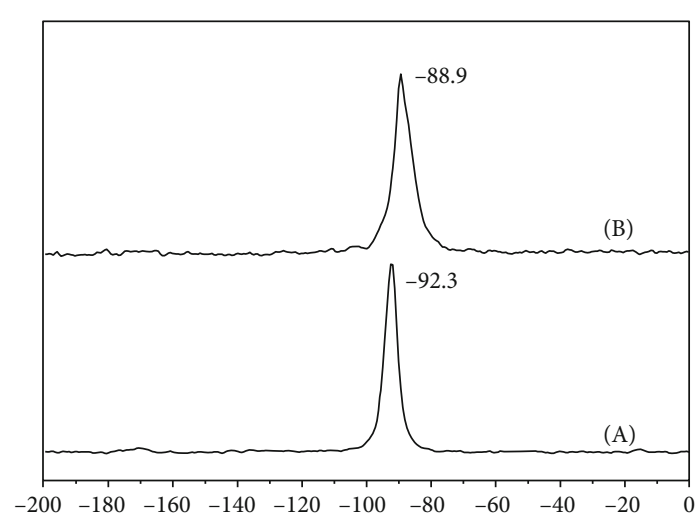

(a) Chemical shift (ppm)

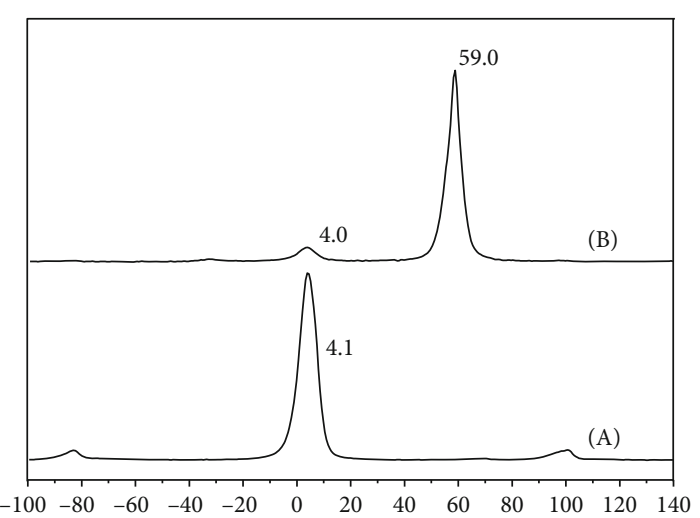

(b) Chemical shift (ppm)

FIGURE 5: ${ }^{29} \mathrm{Si}$ solid-state magic-angle spinning (MAS) nuclear magnetic resonance $\left({ }^{29}\right.$ SiMAS NMR) spectra of the halloysite and zeolite NaA (a). ${ }^{27} \mathrm{Al}$ solid-state magic-angle spinning (MAS) nuclear magnetic resonance ( ${ }^{27} \mathrm{Al}$ MAS NMR) spectra of the halloysite and zeolite NaA (b).

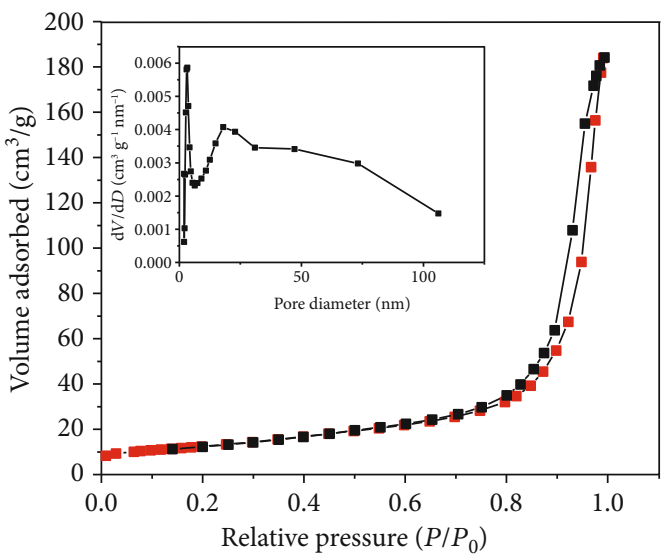

(a)

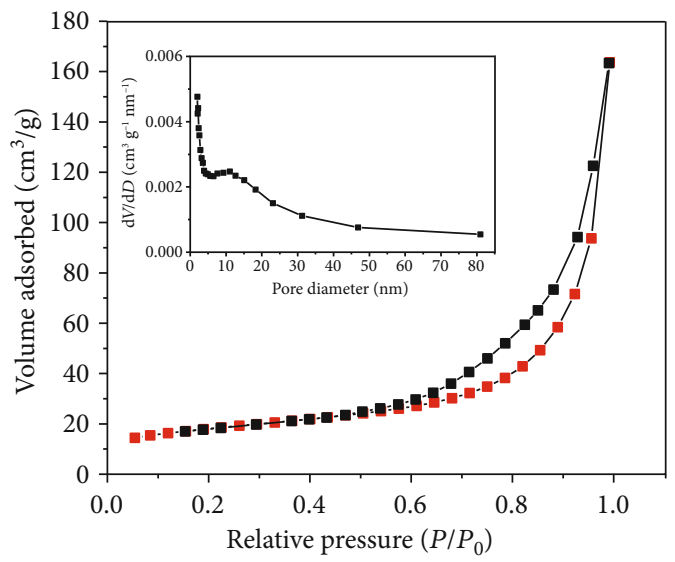

(b)

FIGURE 6: $\mathrm{N}_{2}$ adsorption-desorption isotherms and pore size distribution of the halloysite and zeolite NaA (estimated from the BJH method) of halloysite (a) and zeolite $\mathrm{NaA}(\mathrm{b})$.

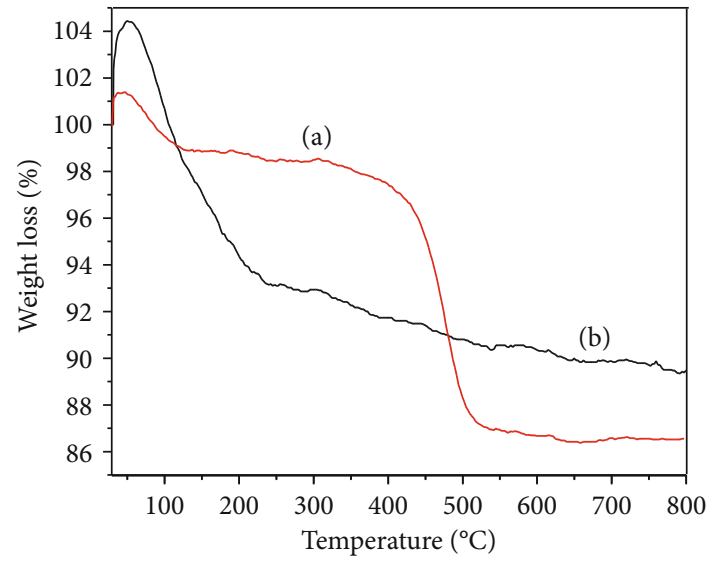

FIgURE 7: TG curves of halloysite (a) and zeolite NaA (b).

second-order model was $111 \mathrm{mgg}^{-1}$, and the experimental adsorption capacity $\left(q_{\mathrm{e}}\right.$, Exp) was $106 \mathrm{mg} \mathrm{g}^{-1}$. It was revealed that the pseudo-second-order kinetics model can successfully predict the adsorption capacity.
3.2.3. Adsorption Isotherm. Both Langmuir and Freundlich models were used for the evaluation of the experimental results. The linear form of the Langmuir equation is given as

$$
\frac{C_{\mathrm{e}}}{q_{\mathrm{e}}}=\frac{1}{K_{\mathrm{L}} q_{\max }}+\frac{C_{\mathrm{e}}}{q_{\max }},
$$

where $q_{\mathrm{e}}\left(\mathrm{mgg}^{-1}\right)$ is the equilibrium amount of $\mathrm{F}^{-}$adsorption by zeolite $\mathrm{NaA}, C_{\mathrm{e}}\left(\mathrm{mgL}^{-1}\right)$ is the equilibrium $\mathrm{F}^{-}$ concentration in the solution, $q_{\max }(\mathrm{mg} / \mathrm{g})$ is the maximum adsorption of $\mathrm{F}^{-}$, and $K_{\mathrm{L}}\left(\mathrm{L} \mathrm{mg}^{-1}\right)$ is the Langmuir constant related to the enthalpy of the process. The values of $q_{\max }$ and $K_{\mathrm{L}}$ can be calculated from the slope and intercept of the plot of $C_{\mathrm{e}} / q_{\mathrm{e}}$ versus $C_{\mathrm{e}}$, respectively.

The linear form of the Freundlich equation can be written as

$\log q_{\mathrm{e}}=\frac{1}{n} \log C_{\mathrm{e}}+\log K_{\mathrm{f}}$ 


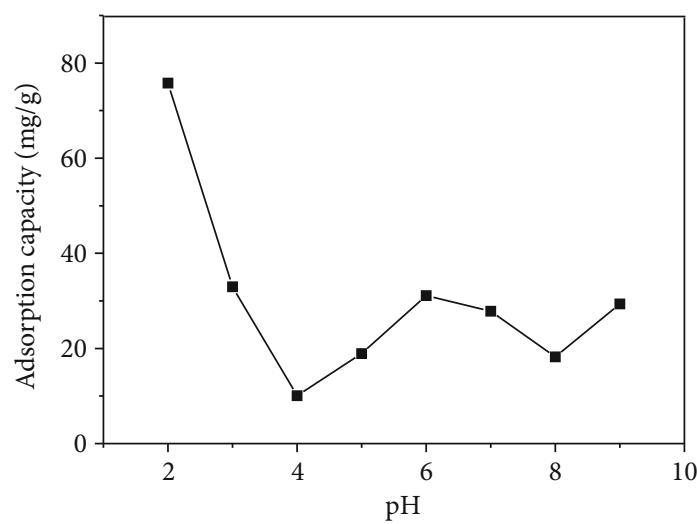

(a)

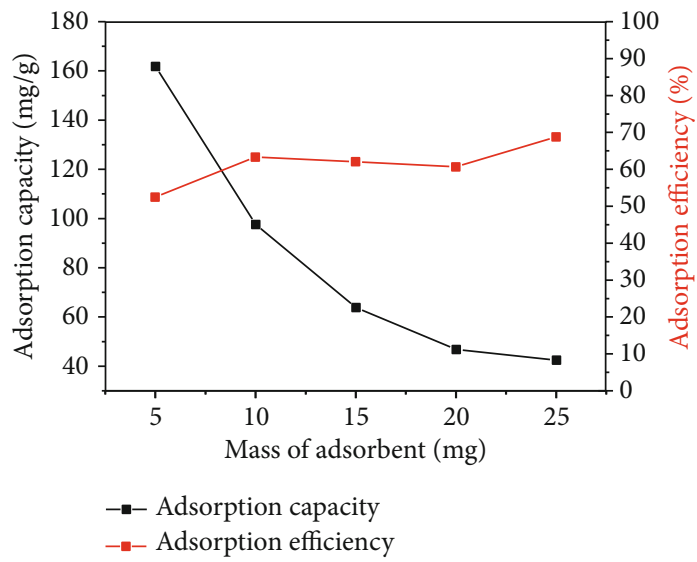

(c)

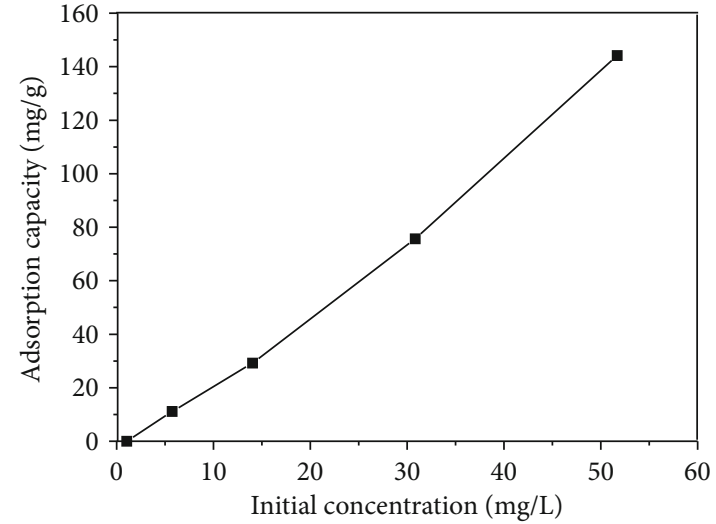

(b)

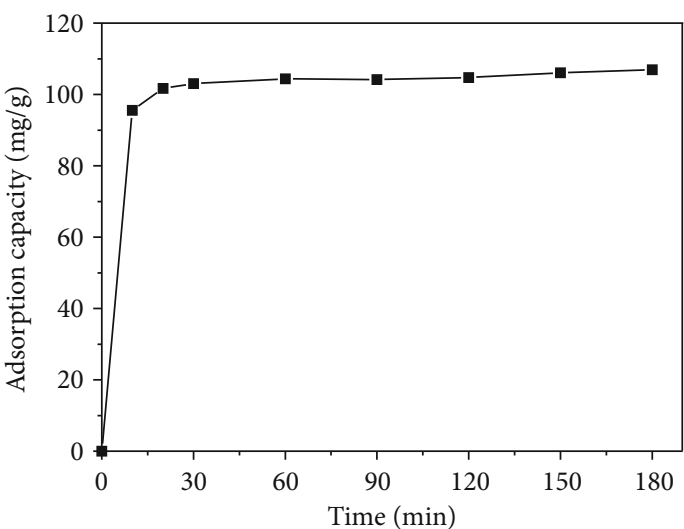

(d)

Figure 8: Effects of $\mathrm{pH}(\mathrm{a})$, initial concentration (b), adsorbent mass (c), and time (d).

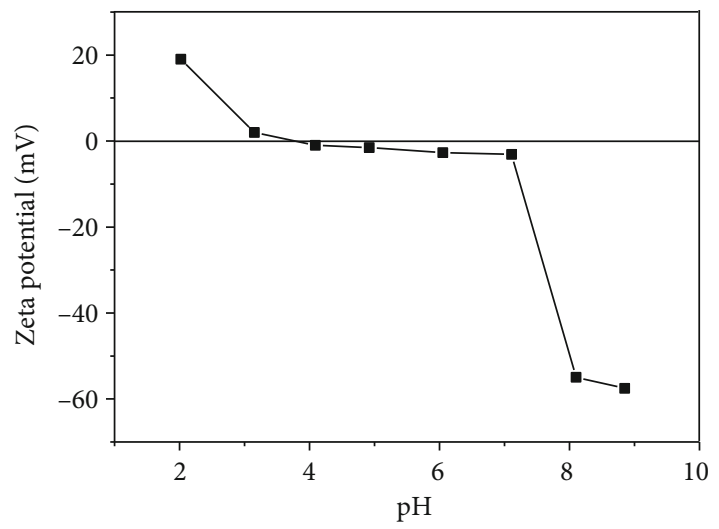

FIGURE 9: Zero charge of zeolite $\mathrm{NaA}$ in different $\mathrm{pH}$ solutions.

where $K_{\mathrm{f}}\left(\mathrm{mgg}^{-1} /\left(\mathrm{mg} \mathrm{L}^{-1}\right)^{1 / n}\right)$ and $n$ are Freundlich constants related to the adsorption capacity and intensity, and $C_{\mathrm{e}}$ $\left(\mathrm{mg} \mathrm{L}^{-1}\right)$ is the equilibrium $\mathrm{F}^{-}$concentration. $K_{\mathrm{f}}$ and $1 / n$ can be calculated by plotting $\log q_{\mathrm{e}}$ versus $\log C_{\mathrm{e}}$. Higher values of $K_{\mathrm{f}}$ reflect a higher affinity for $\mathrm{F}^{-}$. Favorable adsorption is indicated when $0.1<1 / n<1$, whereas unfavorable adsorption takes place when $1 / n>2$.

The linear models of Langmuir and Freundlich were fitted to the experimental data (Fig. S3), and their parameters are reported in Table 3 . The results compiled in Table 3 show that the Freundlich model fitted very well to the experimental data, showing the higher $R^{2}$ value (0.989). Additionally, the Freundlich isotherm is an empirical equation assuming that the adsorption process takes place on a heterogeneous surface through a multilayer adsorption mechanism, where stronger binding sites are occupied first, and the binding strength is related to the concentration of fluoride at equilibrium [53].

3.2.4. Adsorption Mechanism. As mentioned in the literature [54], the adsorption mechanism of an adsorption process may be assumed to involve three sequential steps: (i) film diffusion, (ii) pore diffusion or intraparticle diffusion, and (iii) adsorption of the adsorbate ions on the interior surface of the adsorbent.

The diffusion mechanism of fluoride onto zeolite $\mathrm{NaA}$ was investigated by applying the intraparticle diffusion model proposed by Weber and Morris [55]. This model is 
TABle 1: Previous studies for fluoride removal from water.

\begin{tabular}{|c|c|c|c|c|}
\hline Adsorbent & Type of water & $\begin{array}{l}\text { Adsorption capacity } \\
\left(\mathrm{mg} \mathrm{g}^{-1}\right)\end{array}$ & $\begin{array}{l}\text { Contact } \\
\text { time }\end{array}$ & References \\
\hline $\mathrm{Al}(\mathrm{III})-\mathrm{Zr}$ (III) binary oxide & Aqueous solutions & 114.5 & $4 \mathrm{~h}$ & {$[48]$} \\
\hline Regenerated aluminum oxide-coated media & Aqueous solutions & 34.24 & 5 days & {$[49]$} \\
\hline $\begin{array}{l}\text { 3D hierarchical amorphous aluminum oxide } \\
\text { microspheres }\end{array}$ & Aqueous solutions & 126.9 & $600 \min$ & {$[50]$} \\
\hline Synthetic Fe-Mg-La trimetal nanocomposite & Aqueous solutions & 47.2 & - & [51] \\
\hline $\mathrm{TiO}_{2}-\mathrm{ZrO}_{2}$ & $\begin{array}{c}\text { Groundwater/synthetic water } \\
\text { system }\end{array}$ & 13.1 & $1.5 \mathrm{~h}$ & {$[52]$} \\
\hline Zeolite $\mathrm{NaA}$ & Aqueous solutions & 161 & $30 \mathrm{~min}$ & $\begin{array}{l}\text { In this } \\
\text { study }\end{array}$ \\
\hline
\end{tabular}

TABLE 2: Kinetics models and related parameters.

\begin{tabular}{|c|c|c|c|c|c|c|}
\hline \multirow{2}{*}{$q_{\mathrm{e}}, \operatorname{Exp}\left(\mathrm{mgg}^{-1}\right)$} & \multicolumn{3}{|c|}{ Pseudo-first-order } & \multicolumn{3}{|c|}{ Pseudo-second-order } \\
\hline & $q_{\mathrm{e}}, \mathrm{cal}\left(\mathrm{mg} \mathrm{g}^{-1}\right)$ & $k_{1}\left(\min ^{-1}\right)$ & $R^{2}$ & $q_{\mathrm{e}}, \mathrm{cal}\left(\mathrm{mg} \mathrm{g}^{-1}\right)$ & $k_{2}\left(\mathrm{~g} \cdot \mathrm{mg} \min ^{-1}\right)$ & $R^{2}$ \\
\hline 106 & 9.85 & 0.018 & 0.862 & 111 & $6.23 \times 10^{-3}$ & 0.999 \\
\hline
\end{tabular}

TABLE 3: Related parameters determined from isotherm models.

\begin{tabular}{lccc}
\hline Isotherm & \multicolumn{3}{c}{ Model parameters } \\
\hline \multirow{2}{*}{ Langmuir } & $q_{\max }(\mathrm{mg} / \mathrm{g})$ & $K_{\mathrm{L}}(\mathrm{L} / \mathrm{mg})$ & $R^{2}$ \\
& - & - & 0.953 \\
Freundlich & $K_{\mathrm{f}}\left(\mathrm{mg} \mathrm{g}^{-1} /\left(\mathrm{mg} \mathrm{L}^{-1}\right)^{1 / n}\right)$ & $n$ & $R^{2}$ \\
& 2.558 & 0.720 & 0.989 \\
\hline
\end{tabular}

based on Fick's second law of diffusion, and it can be formulated as follows:

$$
q_{t}=k_{\mathrm{pi}} t^{1 / 2}+c
$$

where $k_{\mathrm{pi}}$ is the intraparticle diffusion rate constant (mg g ${ }^{1} \min ^{-1 / 2}$ ) and $c$ reflects the boundary layer thickness, which can be obtained from the linear plots of $q_{t}$ versus $t^{1 / 2}$.

If the adsorption process follows the intraparticle diffusion model, then $q_{t}$ versus $t^{1 / 2}$ will be linear. If the plot passes through the origin, then intraparticle diffusion is the sole rate-limiting step. Otherwise, some other mechanism along with intraparticle diffusion is also involved.

Multilinearity is apparent in the plots obtained from the kinetics study (Figure 8 and Fig. S4), and this suggests that intraparticle diffusion was present, but it was not the ratelimiting step of the adsorption of $\mathrm{F}^{-}$onto zeolite NaA. These plots indicate that three steps occurred in the process. In the first step (0-10 $\mathrm{min})$, the external surface adsorption or the instantaneous adsorption occurred. In the second portion (10-30 min), there was a gradual adsorption stage where intraparticle diffusion was rate-limiting. In the final equilibrium stage after $30 \mathrm{~min}$, intraparticle diffusion starts to slow down due to a decreasing concentration gradient between the bulk solution and the adsorbent surface [56]. The parameters of the intraparticle diffusion model are shown in
Table 4 . The $k_{\mathrm{pi}}$ values decreased while the $c$ values increased from the first stage through the third stage. The increase in $c$ values is due to the increase in the boundary layer thickness and the driving force for adsorption associated with the initial $\mathrm{F}^{-}$concentration $[57,58]$.

Furthermore, the results of our studies on the adsorption mechanism indicate that the adsorption consists of both physisorption and chemisorption. At $\mathrm{pH} 2$, the charge of zeolite $\mathrm{NaA}$ is positive (zeta potential: $19.05 \mathrm{mV}$ ), and the adsorption capacity of zeolite $\mathrm{NaA}$ is the highest. When the adsorption process is operated at lower $\mathrm{pH}$ range, several reactions are expressed in Equations (7), (8), and (9). However, the adsorption capacities at higher $\mathrm{pH}$ values of 3-9 were irregular (charges of adsorbent are negative). These data indicate that electrostatic attraction promotes the ion exchange substantially at $\mathrm{pH} 2$. Electrostatic attraction and ion exchange are dominant for the adsorption mechanisms. According to the FT-IR spectrum of zeolite $\mathrm{NaA}$ after adsorption (Figure $4 \mathrm{c}$ ), the changes of the band intensities and wavenumber shifts mainly appear in the region of $500-750 \mathrm{~cm}^{-1}$, which are related to $\mathrm{Al}-\mathrm{O}$ groups and double rings (D4R and D6R) in the framework structures. This implies that the strong interaction of fluoride ions with $\mathrm{Al}-\mathrm{O}$ groups and the framework structure may be the reason for changes in the related band intensities and wavenumber shifts.

$$
\begin{gathered}
\text { Zeo-AlOH }+\mathrm{H}^{+} \Leftrightarrow \text { Zeo-AlOH}{ }_{2}^{+} \\
\mathrm{Zeo}-\mathrm{AlOH}_{2}^{+}+\mathrm{F}^{+} \Leftrightarrow \mathrm{Zeo}-\mathrm{AlF} \\
\mathrm{Zeo}-\mathrm{AlOH}+\mathrm{F}^{+} \Leftrightarrow \mathrm{Zeo}-\mathrm{AlF}+\mathrm{OH}^{-}
\end{gathered}
$$

3.3. Regeneration of Zeolite NaA. The adsorbent was subjected to fluoride adsorption experiment to determine the fluoride removal efficiency after regeneration (Figure 10). The adsorption experiments were conducted by using an 
TABLE 4: Related parameters determined from intraparticle diffusion models.

\begin{tabular}{lccc}
\hline & First stage & Second stage & Third stage \\
\hline$k_{\mathrm{pi}}\left(\mathrm{mg} \mathrm{g}^{-1} \mathrm{~min}^{-1 / 2}\right)$ & 30.21 & 3.314 & 0.4509 \\
$c\left(\mathrm{mg} \mathrm{g}^{-1}\right)$ & 0 & 85.60 & 100.37 \\
$R^{2}$ & 1 & 0.9214 & 0.8010 \\
\hline
\end{tabular}

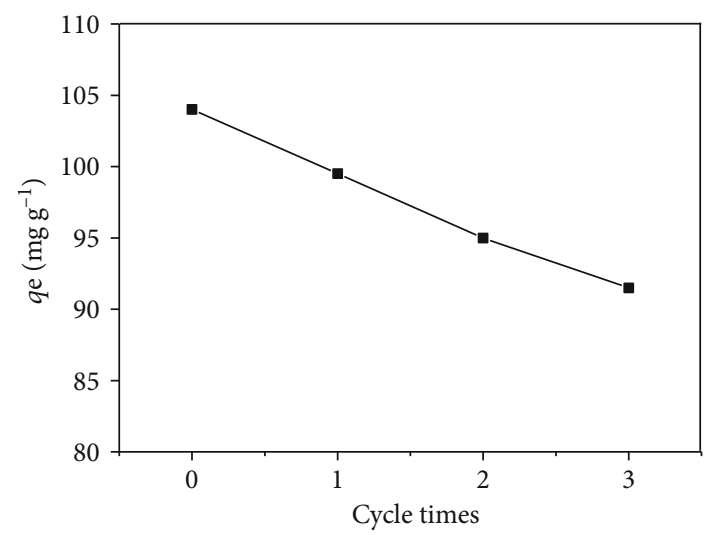

FIGURE 10: Effect of regeneration on equilibrium adsorption capacity.

initial fluoride concentration of $20 \mathrm{mg} \mathrm{L}^{-1}$ at $\mathrm{pH} 2.0$ with $5 \mathrm{mg} / 50 \mathrm{~mL}$ of adsorbent with $1 \mathrm{~h}$ of contact time. This process was repeated 3 times. After the first cycle, the adsorption capacity dropped from $104 \mathrm{mgg}^{-1}$ to $99.5 \mathrm{mg} \mathrm{g}^{-1}$. After the third cycle, the adsorption capacity was still up to $88 \%$ at $91.5 \mathrm{mg} \mathrm{g}^{-1}$. The decrease in the fluoride removal efficiency after regeneration may be due to the treatment with high alkaline of the regenerating media, and the details need to be further investigated.

\section{Conclusion}

The hierarchy flowerlike zeolite was synthesized successfully from natural halloysite with $\mathrm{NaOH}$ by hydrothermal methods. We employed several characterization methods for the raw and as-prepared materials, including XRD, FTIR, HRTEM, and NMR for investigating the morphology and the structure in detail. It could be seen that silicon atoms dissociate from halloysite, so halloysite changes its internal structure and morphology gradually in the course of the reaction under moderate conditions $\left(2 \mathrm{wt} \% \mathrm{NaOH}, 120^{\circ} \mathrm{C}\right)$. The adsorption performance showed that the hierarchical flowerlike zeolite is an efficient material for fluoride removal: the adsorption isotherms showed that the sorption capacity of fluoride is $106 \mathrm{mg} / \mathrm{g}$ at the equilibrium fluoride concentration of $20 \mathrm{mg} / \mathrm{L}$, and the maximum adsorption capacity is $161 \mathrm{mg} / \mathrm{g}$ in batch adsorption study. The equilibrium data were best described by the Freundlich isotherm model, and the adsorption kinetics were best described by pseudosecond-order kinetics. The adsorption mechanism was studied using the intraparticle diffusion model and FT-IR characterization. Combining the effect of $\mathrm{pH}$ and the adsorption isotherm, the results suggested that the mechanism is based on electrostatic attraction and ion exchange. And it is possible to regenerate zeolite $\mathrm{NaA}$ with $\mathrm{NaOH}$ solution treatment. It is concluded that the prepared zeolite from halloysite can be used as a low-cost and relatively effective adsorbent for the removal of fluoride from polluted water.

\section{Data Availability}

The data used to support the findings of this study are available from the corresponding author upon request.

\section{Conflicts of Interest}

The authors declare no conflict of interest.

\section{Acknowledgments}

The research work was financially supported by National Natural Science Foundation of China (Nos. 41472217 and 41521001).

\section{Supplementary Materials}

Fig. S1: growing process, $12 \mathrm{~h}$ (A), $16 \mathrm{~h}$ (B), and $24 \mathrm{~h}(\mathrm{C})$. Fig. S2: pseudo-first-order kinetic plots (a) and pseudo-secondorder kinetic plots (b) for the adsorption. Fig. S3: Langmuir model (a) and Freundlich model (b). Fig. S4: plot of the intraparticle diffusion model for adsorption of fluorine adsorbed onto zeolite NaA. Fig. S5: this is a flowchart for synthesizing zeolite from raw nanohalloysite by using hydrothermal methods. (Supplementary Materials)

\section{References}

[1] S. L. Burkett and M. E. Davis, "Mechanisms of structure direction in the synthesis of pure-silica zeolites. 1. Synthesis of TPA/Si-ZSM-5," Chemistry of Materials, vol. 7, no. 5, pp. 920-928, 2002.

[2] M. Y. Kustova, A. Kustov, S. E. Christiansen, K. T. Leth, S. B. Rasmussen, and C. H. Christensen, "Cu-ZSM-5, Cu-ZSM-11, and Cu-ZSM-12 catalysts for direct NO decomposition," Catalysis Communications, vol. 7, no. 9, pp. 705-708, 2006.

[3] I. Schmidt, A. Boisen, E. Gustavsson et al., "Carbon nanotube templated growth of mesoporous zeolite single crystals," Chemistry of Materials, vol. 13, no. 12, pp. 4416-4418, 2001.

[4] A. Boisen, I. Schmidt, A. Carlsson, S. Dahl, M. Brorson, and C. J. H. Jacobsen, "TEM stereo-imaging of mesoporous zeolite single crystals," Chemical Communications, vol. 8, no. 8, pp. 958-959, 2003.

[5] V. Gia-Thanh and D. Trong-On, "A new route for the synthesis of uniform nanozeolites with hydrophobic external surface in organic solvent medium," Journal of the American Chemical Society, vol. 129, no. 13, pp. 3810-3811, 2007.

[6] Y. Zhao, B. Zhang, X. Zhang, J. Wang, J. Liu, and R. Chen, "Preparation of highly ordered cubic NaA zeolite from halloysite mineral for adsorption of ammonium ions," Journal of Hazardous Materials, vol. 178, no. 1-3, pp. 658-664, 2010.

[7] F. N. Gu, F. Wei, J. Y. Yang et al., "New strategy to synthesis of hierarchical mesoporous zeolites," Chemistry of Materials, vol. 22 , no. 8, pp. 2442-2450, 2010. 
[8] M. Choi, K. Na, J. Kim, Y. Sakamoto, O. Terasaki, and R. Ryoo, "Stable single-unit-cell nanosheets of zeolite MFI as active and long-lived catalysts," Nature, vol. 461, no. 7261, pp. 246-249, 2009.

[9] E. A. Abdelrahman and R. M. Hegazey, "Facile synthesis of $\mathrm{HgO}$ nanoparticles using hydrothermal method for efficient photocatalytic degradation of crystal violet dye under UV and sunlight irradiation," Journal of Inorganic and Organometallic Polymers and Materials, vol. 29, no. 2, article 1005, pp. 346-358, 2019.

[10] E. A. Abdelrahman, D. A. Tolan, and M. Y. Nassar, "A tunable template-assisted hydrothermal synthesis of hydroxysodalite zeolite nanoparticles using various aliphatic organic acids for the removal of zinc (II) ions from aqueous media," Journal of Inorganic and Organometallic Polymers and Materials, vol. 29, no. 1, pp. 229-247, 2019.

[11] A. Elshad, A. Joshi, W. Wei, Y. Zhao, and Y. Lvov, "Enlargement of halloysite clay nanotube lumen by selective etching of aluminum oxide," ACS Nano, vol. 6, no. 8, pp. 7216-7226, 2012.

[12] H. Biglari, A. Chavoshani, N. Javan, and A. Hossein Mahvi, "Geochemical study of groundwater conditions with special emphasis on fluoride concentration, Iran," Desalination \& Water Treatment, vol. 57, no. 47, pp. 22392-22399, 2016.

[13] D. Li, X. Gao, Y. Wang, and W. Luo, "Diverse mechanisms drive fluoride enrichment in groundwater in two neighboring sites in northern China," Environmental Pollution, vol. 237, pp. 430-441, 2018.

[14] W. M. Edmunds and P. L. Smedley, "Fluoride in natural waters," in Essentials of Medical Geology, pp. 311-336, Springer, 2013.

[15] S. Su, D. Li, Q. Zhang, R. Xiao, F. Huang, and J. Wu, “Temporal trend and source apportionment of water pollution in different functional zones of Qiantang River, China," Water Research, vol. 45, no. 4, pp. 1781-1795, 2011.

[16] K. Cherukumilli, C. Delaire, S. Amrose, and A. J. Gadgil, "Factors governing the performance of bauxite for fluoride remediation of groundwater," Environmental Science \& Technology, vol. 51, no. 4, pp. 2321-2328, 2017.

[17] A. A. Mohammadi, M. Yousefi, M. Yaseri, M. Jalilzadeh, and A. H. Mahvi, "Skeletal fluorosis in relation to drinking water in rural areas of West Azerbaijan, Iran," Scientific Reports, vol. 7, no. 1, p. 17300, 2017.

[18] M. Yousefi, M. Ghoochani, and M. A. Hossein, "Health risk assessment to fluoride in drinking water of rural residents living in the Poldasht city, northwest of Iran," Ecotoxicology \& Environmental Safety, vol. 148, pp. 426-430, 2017.

[19] A. Rahmani, K. Rahmani, S. Dobaradaran, A. H. Mahvi, R. Mohamadjani, and H. Rahmani, "Child dental caries in relation to fluoride and some inorganic constituents in drinking water in Arsanjan, Iran," Fluoride, vol. 43, no. 3, pp. 179186, 2010.

[20] T. Bacquart, S. Frisbie, E. Mitchell et al., "Multiple inorganic toxic substances contaminating the groundwater of Myingyan township, Myanmar: arsenic, manganese, fluoride, iron, and uranium," Science of the Total Environment, vol. 517, pp. 232-245, 2015.

[21] A. Farooqi, H. Masuda, and N. Firdous, "Toxic fluoride and arsenic contaminated groundwater in the Lahore and Kasur districts, Punjab, Pakistan and possible contaminant sources," Environmental Pollution, vol. 145, no. 3, pp. 839-849, 2007.
[22] A. Manouchehr, K. Mueller, K. C. Abbaspour et al., "Statistical modeling of global geogenic fluoride contamination in groundwaters," Environmental Science \& Technology, vol. 42, no. 10, pp. 3662-3668, 2008.

[23] D. Mondal, S. Gupta, D. V. Reddy, and G. Dutta, "Fluoride enrichment in an alluvial aquifer with its subsequent effect on human health in Birbhum district, West Bengal, India," Chemosphere, vol. 168, pp. 817-824, 2017.

[24] Y. Ding, YanhuiGao, H. Sun et al., "The relationships between low levels of urine fluoride on children's intelligence, dental fluorosis in endemic fluorosis areas in Hulunbuir, Inner Mongolia, China," Journal of Hazardous Materials, vol. 186, no. 23, pp. 1942-1946, 2011.

[25] R. Naidu, V. A. Arias Espana, Y. Liu, and J. Jit, "Emerging contaminants in the environment: risk-based analysis for better management," Chemosphere, vol. 154, pp. 350-357, 2016.

[26] E. Bazrafshan, "Application of electrocoagulation process using iron and aluminum electrodes for fluoride removal from aqueous environment," E-Journal of Chemistry, vol. 9, no. 4, pp. 2297-2308, 2015.

[27] A. Meenakshi and R. C. Maheshwari, "Fluoride in drinking water and its removal," Journal of Hazardous Materials, vol. 137, no. 1, pp. 456-463, 2006.

[28] M. J. Larsen and E. I. F. Pearce, "Defluoridation of drinking water by boiling with brushite and calcite," Caries Research, vol. 36, no. 5, pp. 341-346, 2002.

[29] A. Lhassani, "Selective demineralization of water by nanofiltration application to the defluorination of brackish water," Water Research, vol. 35, no. 13, pp. 3260-3264, 2001.

[30] H. Garmes, F. Persin, J. Sandeaux, G. Pourcelly, and M. Mountadar, "Defluoridation of groundwater by a hybrid process combining adsorption and Donnan dialysis," Desalination, vol. 145, no. 1-3, pp. 287-291, 2018.

[31] P. I. Ndiayea, P. Moulin, L. Dominguez, J. C. Millet, and F. Charbit, "Removal of fluoride from electronic industrial effluentby RO membrane separation," Desalination, vol. 173, no. 1, pp. 25-32, 2005.

[32] N. I. Chubar, V. F. Samanidou, V. S. Kouts et al., "Adsorption of fluoride, chloride, bromide, and bromate ions on a novel ion exchanger," Journal of Colloid and Interface Science, vol. 291, no. 1, pp. 67-74, 2005.

[33] C. Díaz-Nava, M. Solache-Ríos, and M. T. Olguín, "Sorption of fluoride ions from aqueous solutions and well drinking water by thermally treated hydrotalcite," Separation Science and Technology, vol. 38, no. 1, pp. 131-147, 2003.

[34] Y. Tao, H. Kanoh, L. Abrams, and K. Kaneko, "Mesoporemodified zeolites: preparation, characterization, and applications," Chemical reviews, vol. 106, no. 3, pp. 896-910, 2006.

[35] E. A. Abdelrahman and R. Hegazey, "Exploitation of Egyptian insecticide cans in the fabrication of $\mathrm{Si} / \mathrm{Fe}$ nanostructures and their chitosan polymer composites for the removal of $\mathrm{Ni}(\mathrm{II})$, $\mathrm{Cu}(\mathrm{II})$, and $\mathrm{Zn}(\mathrm{II})$ ions from aqueous solutions," Composites Part B: Engineering, vol. 166, pp. 382-400, 2019.

[36] M. Y. Nassar, E. A. Abdelrahman, A. A. Aly, and T. Y. Mohamed, "A facile synthesis of mordenite zeolite nanostructures for efficient bleaching of crude soybean oil and removal of methylene blue dye from aqueous media," Journal of Molecular Liquids, vol. 248, pp. 302-313, 2017.

[37] M. Y. Nassar, H. M. Aly, E. A. Abdelrahman, and M. E. Moustafa, "Synthesis, characterization, and biological activity of some novel Schiff bases and their $\mathrm{Co}(\mathrm{II})$ and $\mathrm{Ni}(\mathrm{II})$ complexes: 
a new route for $\mathrm{Co}_{3} \mathrm{O}_{4}$ and $\mathrm{NiO}$ nanoparticles for photocatalytic degradation of methylene blue dye," Journal of Molecular Structure, vol. 1143, pp. 462-471, 2017.

[38] E. A. Abdelrahman and R. Hegazey, "Utilization of waste aluminum cans in the fabrication of hydroxysodalite nanoparticles and their chitosan biopolymer composites for the removal of $\mathrm{Ni}(\mathrm{II})$ and $\mathrm{Pb}(\mathrm{II})$ ions from aqueous solutions: kinetic, equilibrium, and reusability studies," Microchemical Journal, vol. 145, pp. 18-25, 2019.

[39] E. A. Abdelrahman, "Synthesis of zeolite nanostructures from waste aluminum cans for efficient removal of malachite green dye from aqueous media," Journal of Molecular Liquids, vol. 253, pp. 72-82, 2018.

[40] M. Y. Nassar and E. A. Abdelrahman, "Hydrothermal tuning of the morphology and crystallite size of zeolite nanostructures for simultaneous adsorption and photocatalytic degradation of methylene blue dye," Journal of Molecular Liquids, vol. 242, pp. 364-374, 2017.

[41] H. M. Aly, M. E. Moustafa, and E. A. Abdelrahman, "Influence-of-aluminum-source-on-the-synthesis-of-nanosizedzsm5-zeolite," Der Chemica Sinica, vol. 2, no. 4, pp. 166-173, 2011.

[42] E. A. Abdelrahman, R. Hegazey, and R. E. El-Azabawy, "Efficient removal of methylene blue dye from aqueous media using $\mathrm{Fe} / \mathrm{Si}, \mathrm{Cr} / \mathrm{Si}, \mathrm{Ni} / \mathrm{Si}$, and $\mathrm{Zn} / \mathrm{Si}$ amorphous novel adsorbents," Journal of Materials Research and Technology, 2019.

[43] H. M. Aly, M. E. Moustafa, and E. A. Abdelrahman, "Synthesis of mordenite zeolite in absence of organic template," Advanced Powder Technology, vol. 23, no. 6, pp. 757-760, 2012.

[44] C. A. Ríos, C. D. Williams, and M. A. Fullen, "Nucleation and growth history of zeolite LTA synthesized from kaolinite by two different methods," Applied Clay Science, vol. 42, no. 3-4, pp. 446-454, 2009.

[45] M. Thommes, "Physisorption of gases, with special reference to the evaluation of surface area and pore size distribution (IUPAC technical report)," Pure and Applied Chemistry, vol. 38 , no. 1, p. $25,2016$.

[46] A. Ates, "Effect of alkali-treatment on the characteristics of natural zeolites with different compositions," Journal of Colloid and Interface Science, vol. 523, pp. 266-281, 2018.

[47] A. Shukla, Y. H. Zhang, P. Dubey, J. L. Margrave, and S. S. Shukla, "The role of sawdust in the removal of unwanted materials from water," Journal of Hazardous Materials, vol. 95, no. 1-2, pp. 137-152, 2002.

[48] J. Zhu, X. Lin, P. Wu, Q. Zhou, and X. Luo, "Fluoride removal from aqueous solution by $\mathrm{Al}(\mathrm{III})-\mathrm{Zr}(\mathrm{IV})$ binary oxide adsorbent," Applied Surface Science, vol. 357, pp. 91-100, 2015.

[49] R. Buamah, C. A. Oduro, and M. H. Sadik, "Fluoride removal from drinking water using regenerated aluminum oxide coated media," Journal of Environmental Chemical Engineering, vol. 4, no. 1, pp. 250-258, 2016.

[50] D. Kang, S. Tong, X. Yu, and M. Ge, “Template-free synthesis of 3D hierarchical amorphous aluminum oxide microspheres with broccoli-like structure and their application in fluoride removal," RSC Advances, vol. 5, no. 25, pp. 19159-19165, 2015.

[51] P. Chen, T. Wang, Y. Xiao et al., "Efficient fluoride removal from aqueous solution by synthetic Fe Mg La tri-metal nanocomposite and the analysis of its adsorption mechanism," Journal of Alloys and Compounds, vol. 738, pp. 118-129, 2018.
[52] Y. Yu, Z. Zhou, Z. Ding, M. Zuo, J. Cheng, and C. Jing, "Simultaneous arsenic and fluoride removal using $\{201\} \mathrm{TiO}_{2}-\mathrm{ZrO}_{2}$ : fabrication, characterization, and mechanism," Journal of Hazardous Materials, vol. 377, pp. 267-273, 2019.

[53] H. Freundlich, "Über die adsorption in lösungen," Zeitschrift für Physikalische Chemie, vol. 57U, no. 1, pp. 385-470, 1907.

[54] I. A. W. Tan, A. L. Ahmad, and B. H. Hameed, "Adsorption of basic dye on high-surface-area activated carbon prepared from coconut husk: equilibrium, kinetic and thermodynamic studies," Journal of Hazardous Materials, vol. 154, no. 1-3, pp. 337-346, 2008.

[55] W. J. Weber and J. C. Morris, "Kinetics of adsorption on carbon from solution," Journal of the Sanitary Engineering Division, vol. 89, no. 2, pp. 31-60, 1963.

[56] I. A. W. Tan, J. C. Chan, B. H. Hameed, and L. L. P. Lim, "Adsorption behavior of cadmium ions onto phosphoric acid-impregnated microwave-induced mesoporous activated carbon," Journal of Water Process Engineering, vol. 14, pp. 60-70, 2016.

[57] F. Marrakchi, M. J. Ahmed, W. A. Khanday, M. Asif, and B. H. Hameed, "Mesoporous-activated carbon prepared from chitosan flakes via single-step sodium hydroxide activation for the adsorption of methylene blue," International Journal of Biological Macromolecules, vol. 98, pp. 233-239, 2017.

[58] K. K. Beltrame, A. L. Cazetta, P. S. C. de Souza, L. Spessato, T. L. Silva, and V. C. Almeida, "Adsorption of caffeine on mesoporous activated carbon fibers prepared from pineapple plant leaves," Ecotoxicology \& Environmental Safety, vol. 147, pp. 64-71, 2017. 


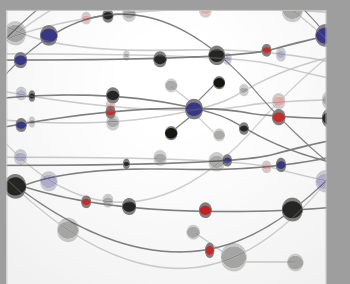

The Scientific World Journal
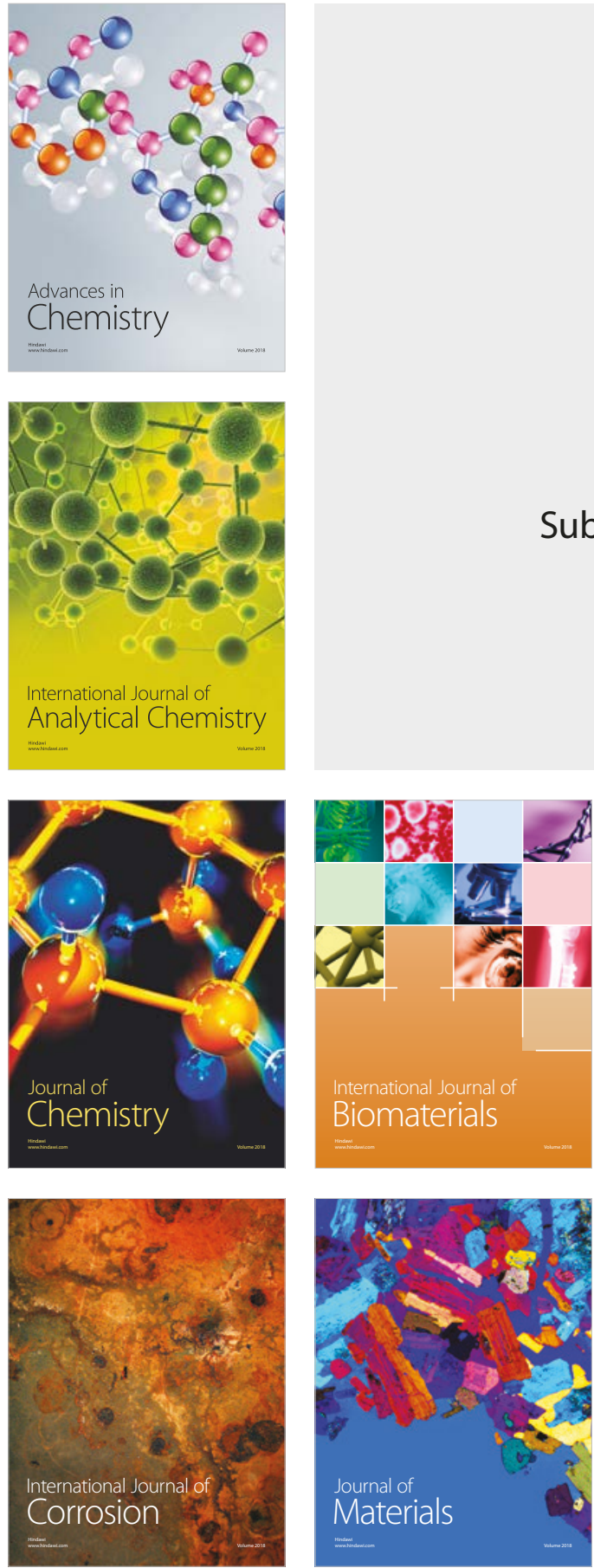

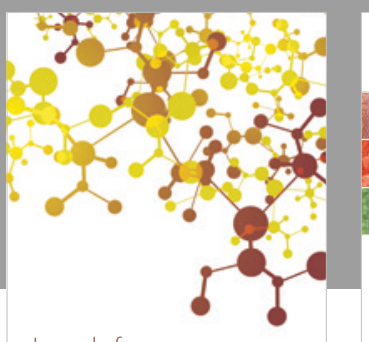

Journal of

Applied Chemistry
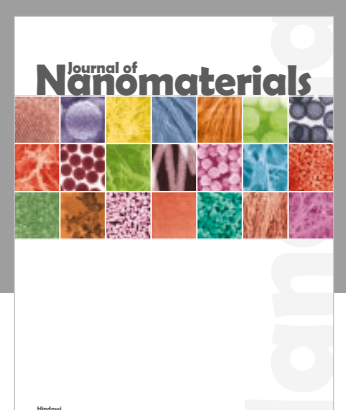

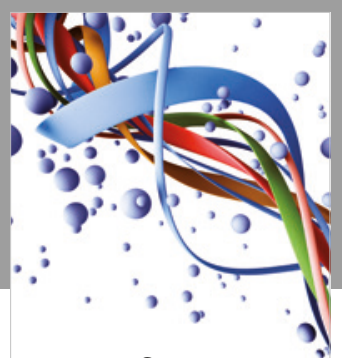

Scientifica

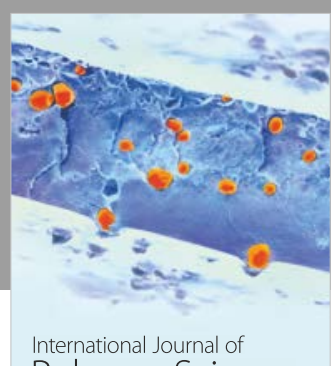

Polymer Science

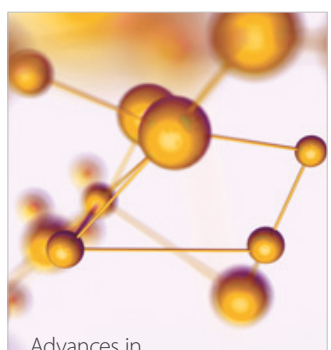

Physical Chemistry
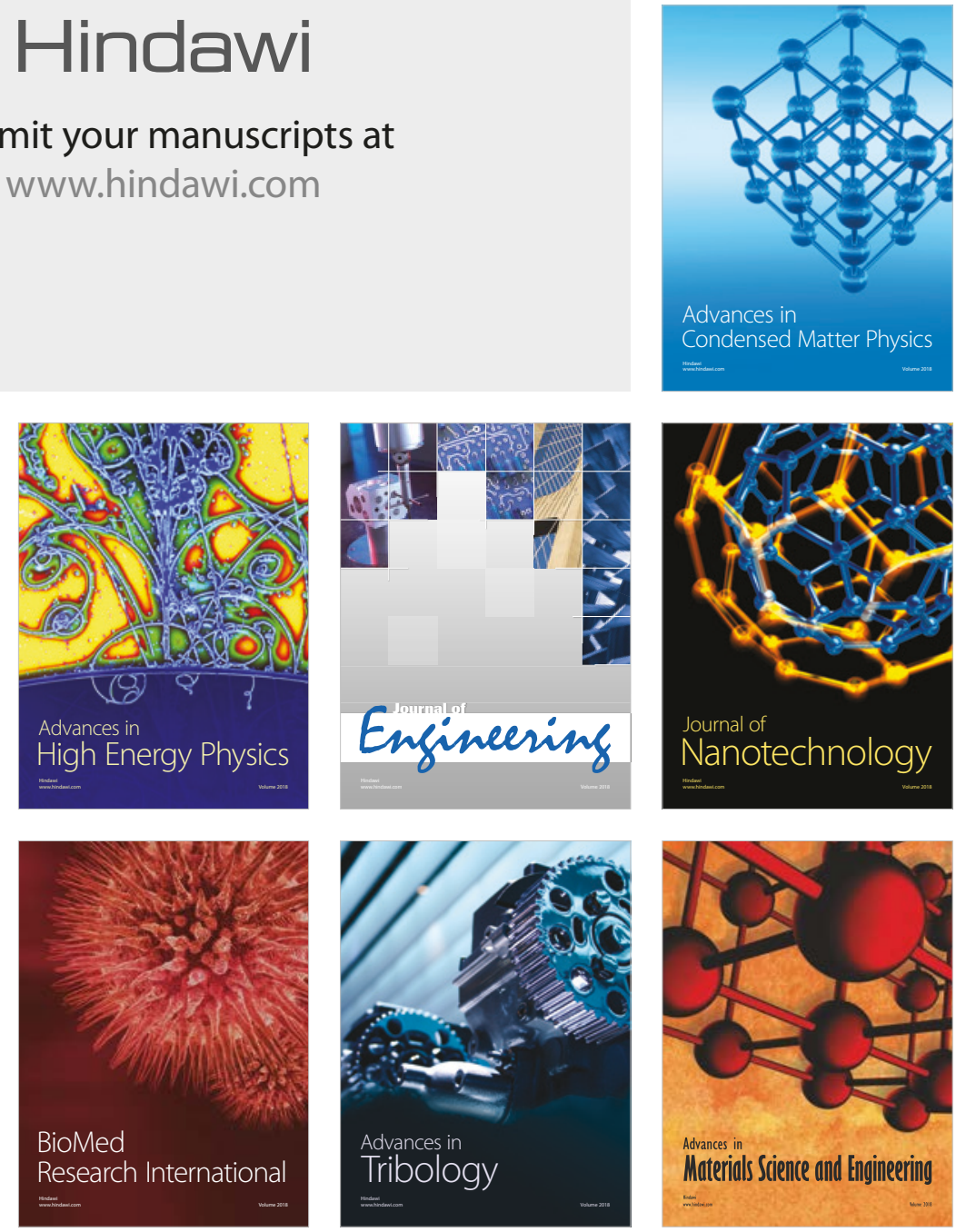